\title{
Incidental detection of a lung perfusion defect suspicious of pulmonary embolism on labelled white blood cell quality control imaging-case report
}

\author{
Osayande Evbuomwan *i] and Gerrit Engelbrecht
}

\begin{abstract}
Background: Incidental findings could be a very important observation in various nuclear medicine studies. There have been few cases of incidental findings of perfusion abnormalities on early quality control images of the lungs during radiolabeled white blood cell studies. This study is the first to detect perfusion defects on the early quality control images of the lungs during a labelled white blood cell study suspicious of pulmonary embolism in an unknown but treated COVID-19 patient.

Case presentation: We present a 40-year-old male who was referred to our department for a nuclear medicine ${ }^{99 m}$ Tc HMPAO-labelled white blood cell study to rule out osteomyelitis of his right foot. Early 5-min quality control images of his lungs revealed two perfusion defects in the right lung. A suspicion of pulmonary embolism was made, and a perfusion only SPECT/CT study the next day confirmed the suspicion of pulmonary embolism in one of the defects, with a possible fissure sign as a differential.

Conclusion: There has been an increase in the incidence of lung perfusion abnormalities and pulmonary embolism during the COVID-19 pandemic. Some of these may be detected as incidental findings on early lung quality control images of radiolabeled white blood cell studies.
\end{abstract}

Keywords: Quality control, White blood cell labelling, Perfusion defect, Pulmonary embolism, Case report

\section{Background}

Scintigraphy with autologous labelled white blood cells (WBCs) is a widely used method to detect sites of infection. There are various quality control $(\mathrm{QC})$ methods used to assess the quality of WBC labelling [1]. Early images of radiotracer distribution in the lungs are one of them [1,2], and this is routinely performed in our facility. Incidental findings could be a very important observation in various nuclear medicine studies. These findings can be identified during imaging, processing or reporting of these studies. In the era of the coronavirus

\footnotetext{
* Correspondence: moreli14@yahoo.com

Nuclear Medicine Department, Universitas Academic Hospital, University of The Free State, Lower ground floor, Logeman Street, Bloemfontein 9301,
} South Africa

disease 2019 (COVID-19) pandemic, there have been suspicious for pulmonary embolism (PE), identified on early technetium 99 metastable hexamethylpropyleneamine oxime $\left({ }^{99 \mathrm{~m}} \mathrm{Tc}\right.$ HMPAO)-labelled WBC QC images of the lungs of a patient unknown to have recently recovered from a previous COVID-19 infection. There have been several documentations in the past revealing that had categorically identified lung perfusion defects suspicious for PE. ated with the disease [3-6]. In this case report, we incidental detection of abnormalities on these early lung QC images $[7,8]$. However, we were not able to 


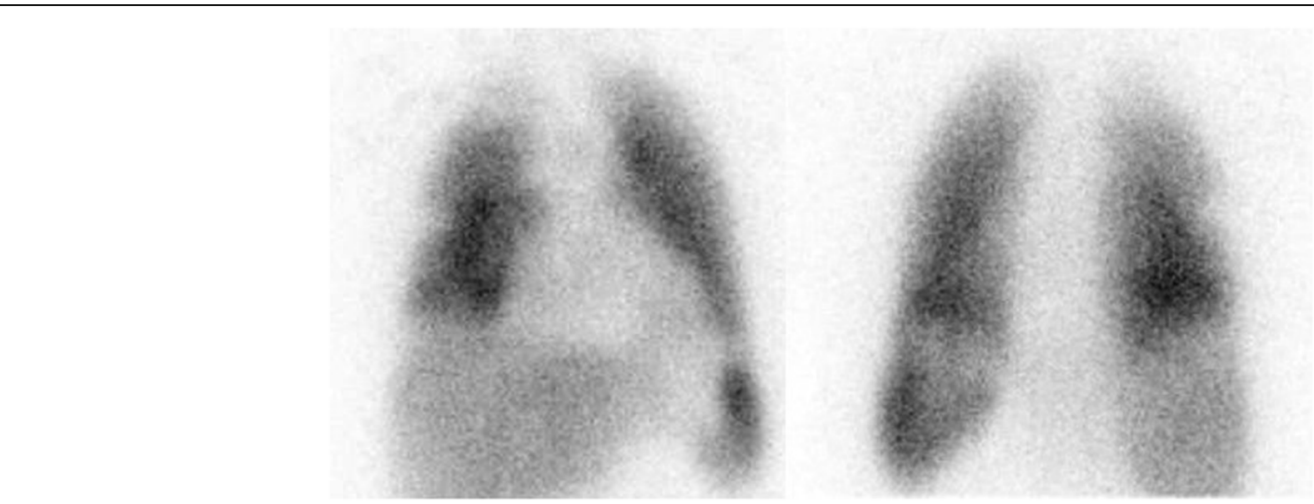

Fig. 1 Anterior and posterior images of the lungs (left and right respectively) 5 min after injecting $25 \mathrm{mCi}$ of technetium 99m-labelled white blood cells

\section{Case presentation}

We present a 40-year-old male who was referred to our facility for labelled WBC imaging to rule out osteomyelitis in his right foot. Early quality control images of his lungs revealed perfusion defects in the lateral and apical segments of his right middle and upper lobes respectively (Fig. 1). After reviewing these images, we informed the referral doctors of a possible suspicion for $\mathrm{PE}$, and thus, a lung perfusion singlephoton emission computed tomography/computed tomography (SPECT/CT) study with ${ }^{99 \mathrm{~m}} \mathrm{Tc}$ macroaggregated albumin (MAA) was booked the next day. We could not perform lung SPECT/CT imaging of the labelled WBC study because we reviewed those early images over an hour after injection of the radiotracer and, by then, clearance of the normal physiological uptake of the radiotracer in the lungs had occurred. The ${ }^{99 \mathrm{~m}}$ Tc MAA lung perfusion only SPECT/CT study revealed a perfusion defect in the lateral segment of the right middle lobe, although close to the major fissure, we could not totally rule out PE (Fig. 2). Unfortunately, we could not confirm if this defect is matched or unmatched on ventilation images, as were not performing lung ventilation studies then, and thus, we reported it as a non-diagnostic finding for PE. It was part of our departmental protocol then not to perform ventilation studies because of the potential increased risk of spread of COVID-19 infection.

A second defect in the anterior segment of the right upper lobe was also demonstrated on the ${ }^{99 \mathrm{~m}}$ Tc MAA lung SPECT/CT images, corresponding to mosaic attenuation changes on CT (Fig. 3). Mosaic attenuation,

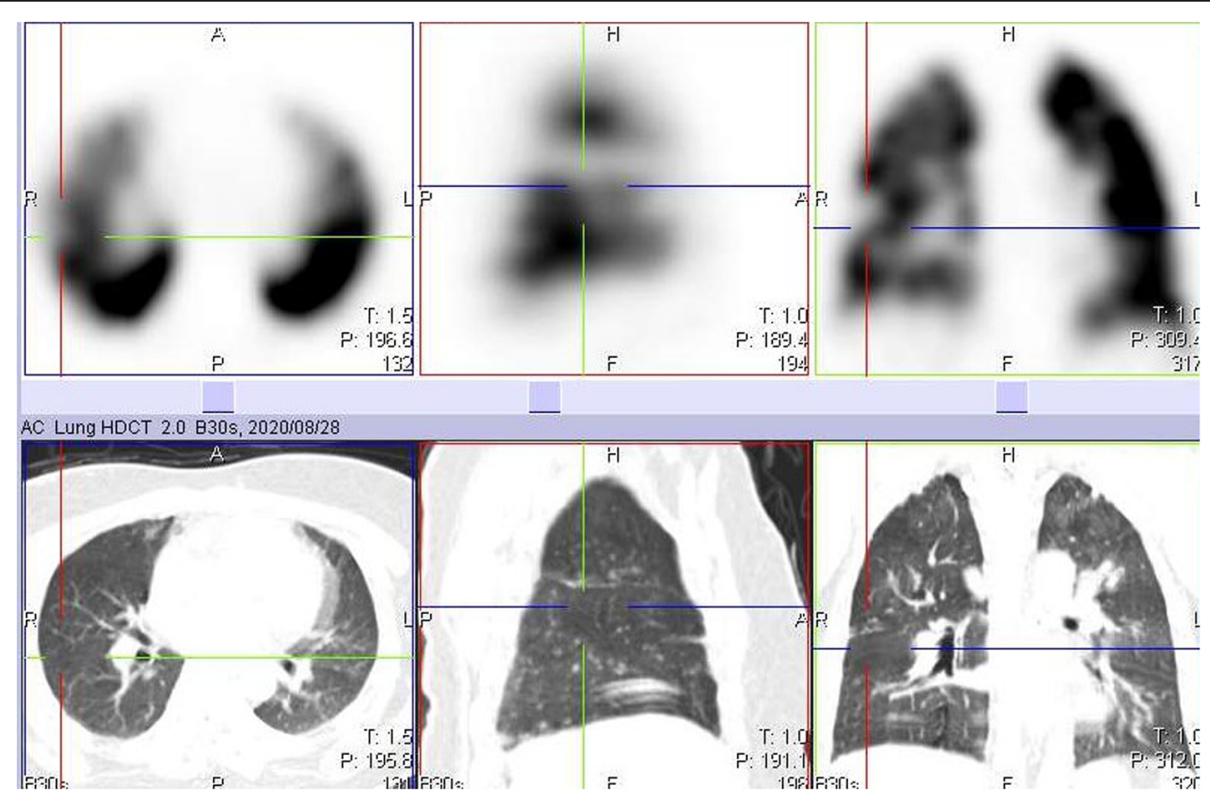

Fig. 2 Axial, coronal and sagittal SPECT images of the lungs showing a large perfusion defect in the lateral segment of the right middle lobe. The corresponding CT images below do not show obvious structural lung changes in that segment 


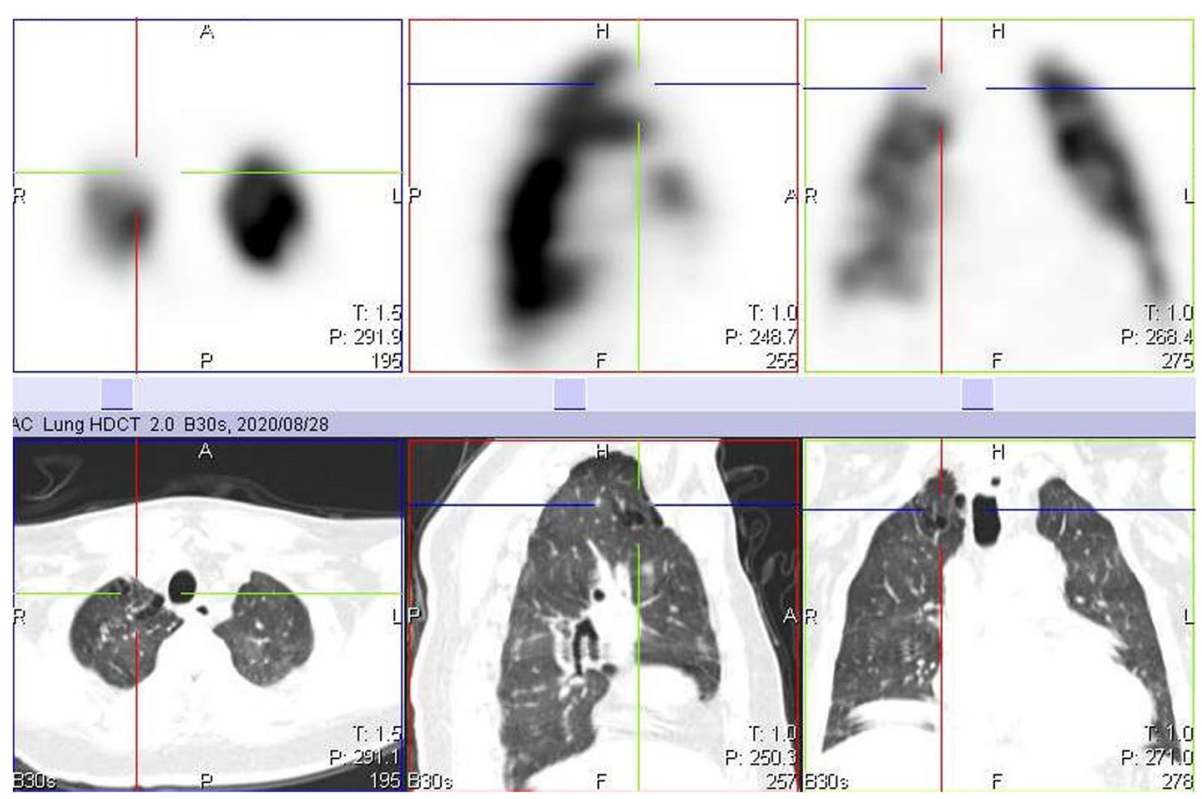

Fig. 3 Axial, coronal and sagittal SPECT images of the lungs showing another large perfusion defect in the apical segment of the right upper lobe. However, the corresponding CT images below show structural lung changes with mosaic attenuation in that segment

although not specific, has also been described in the literature to be associated with perfusion abnormalities in COVID-19 infection [9, 10].

Incidentally, on the CT images, we identified ground glass opacities and linear consolidation in the right lung, with a predominant peripheral distribution (Fig. 4). These radiological findings on lung CT have been well documented to be associated with COVID19 infection $[9,11]$.

This finding, alongside the suspicion for pulmonary embolism and the mosaic attenuation on CT, raised a suspicion for an ongoing or previous COVID-19 infection. Further investigation and clinical history revealed that the patient had just recovered from
COVID-19 infection 2 weeks prior to his referral to our department.

\section{Conclusion}

This case is a very good case for teaching and serves as a reminder that incidental findings in imaging must always be looked out for, besides the primary reason for an imaging study. Quality control imaging of the lungs during radiolabeled WBC studies might not be routinely done in most nuclear medicine centres; however, incidental findings such as those noticed in our study could be missed. We are not sure what the clinical significance of these defects may mean for the patient later on; however, we informed the referral doctor accordingly.

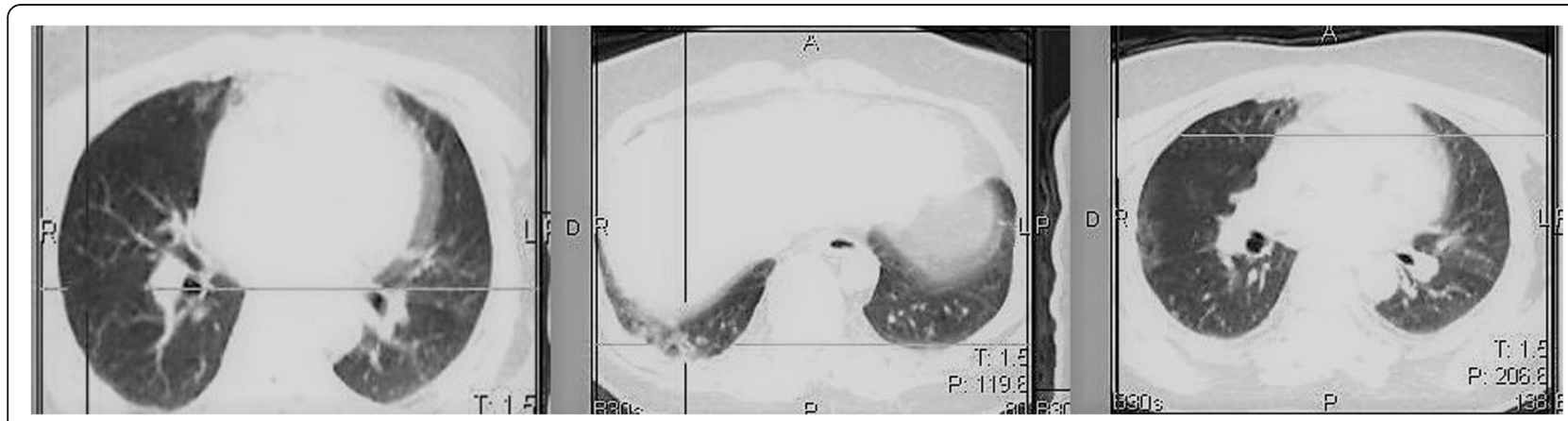

Fig. 4 Axial CT images in different slices showing ground glass opacities in the right lung on the left and right images, with the middle image showing linear consolidation in the right lung. Note the predominant peripheral distribution 


\section{Abbreviations}

WBC: White blood cell; OC: Quality control; COVID-19: Coronavirus disease 2019; PE: Pulmonary embolism; ${ }^{99 m}$ Tc HMPAO: Technetium 99 metastable hexamethylpropyleneamine oxime; SPECT/CT: Single-photon emission computed tomography/computed tomography; MAA: Macroaggregated albumin

\section{Acknowledgements}

With their permission, the authors would like to acknowledge the three radiographers who spotted the perfusion defects on the lung quality control images. They include Helena Oosthuizen, Jenine Lewis and Daniela Johanna Du Toit.

\section{Authors' contributions}

OE was the major contributor in writing the article, and GA was a contributor in writing and proofreading the article. All authors have read and approved the manuscript.

\section{Funding}

There is no source of funding to be declared.

\section{Availability of data and materials}

All data and material of the article are readily available.

\section{Declarations}

Ethics approval and consent to participate

Ethics approval was obtained from the University of the Free State's Health Sciences Research Ethics Committee (HSREC), with reference number UFS-HSD2020/1570/2601. The patient gave an informed consent to participate in this case report.

\section{Consent for publication}

Written consent to publish this information was obtained from the study participant.

\section{Competing interests}

The authors declare that they have no competing interests.

Received: 26 February 2021 Accepted: 23 March 2021

Published online: 01 April 2021

\section{References}

1. De Vries EFJ, Roca M, Jamar F, Israel O, Signore (2010) Guidelines for the labelling of leucocytes with 99mTc-HMPAO. Eur J Nucl Med Mol Imaging 37(4):842-848. https://doi.org/10.1007/s00259-010-1394-4

2. Segall GM, McDougall IR (1986) Diagnostic value of lung uptake of indium111 oxine-labeled white blood cells. Am J Roentgenol 147(3):601-606. https://doi.org/10.2214/ajr.147.3.601

3. Patelli G, Paganoni S, Besana F, Codazzi F, Ronzoni M, Manini S et a (2020) Detection of lung hypoperfusion in Covid-19 patients during recovery by digital imaging quantification. https://doi.org/10.1101/2020. 05.29.20117143

4. Herrmann J, Mori V, Bates JHT, Suki B (2020) Modeling lung perfusion abnormalities to explain early COVID-19 hypoxemia. Nat Commun 11(1): 4883. https://doi.org/10.1038/s41467-020-18672-6

5. Santamarina MG, Boisier D, Contreras R, Baque M, Volpacchio M, Beddings I (2020) COVID-19: a hypothesis regarding the ventilation-perfusion mismatch. Critical Care 24:526

6. Meirelles G d SP (2020) COVID-19: a brief update for radiologists. Radiologia Brasileira 53(5):320-328. https://doi.org/10.1590/0100-3984.2020.0074

7. Palestro CJ, Padilla ML, Swyer AJ, Goldsmith SJ (1992) Diffuse pulmonary uptake of indium-111-labeled leukocytes in drug-induced pneumonitis. J Nucl Med 33(6):1175-1177

8. Love C, Opoku-Agyemang P, Tomas MB, Pugliese PV, Bhargava KK, Palestro CJ (2002) Pulmonary activity on labeled leukocyte images: physiologic, pathologic, and imaging correlation. Radiographics 22(6):1385-1393. https:// doi.org/10.1148/rg.226025038

9. Lang M, Som A, Mendoza DP, Flores EJ, Reid N, Carey D, Li MD, Witkin A, Rodriguez-Lopez JM, Shepard JAO, Little BP (2020) Hypoxaemia related to
COVID-19: vascular and perfusion abnormalities on dual-energy CT. Lancet Infect Dis 20(12):1365-1366. https://doi.org/10.1016/S1473-3099(20)30367-4

10. Lang M, Som A, Carey D, Reid N, Mendoza DP, Flores EJ, Li MD, Shepard JAO, Little BP (2020) Pulmonary vascular manifestations of COVID-19 pneumonia. Radiol Cardiothorac Imaging. 2(3). https://doi.org/10.1148/ryct.2 020200277

11. Wang H, Wei R, Rao G, Zhu J, Song B (2020) Characteristic CT findings distinguishing 2019 novel coronavirus disease (COVID-19) from influenza pneumonia. Eur Radiol. 30(9):4910-4917. https://doi.org/10.1007/s00330020-06880-z

\section{Publisher's Note}

Springer Nature remains neutral with regard to jurisdictional claims in published maps and institutional affiliations.

\section{Submit your manuscript to a SpringerOpen ${ }^{\circ}$ journal and benefit from:}

- Convenient online submission

- Rigorous peer review

- Open access: articles freely available online

- High visibility within the field

- Retaining the copyright to your article

Submit your next manuscript at $\boldsymbol{\nabla}$ springeropen.com 